\title{
CÍRCULO DE CONTROLE DE QUALIDADE COMO FERRAMENTA PARA DIMINUIÇÃO DE CUSTO NUMA INDÚSTRIA DE FIAÇÃO DE ALGODÃO NA CIDADE DE ITUVERAVA
}

GOMES, Ana Carolina da Silva ${ }^{1}$

PENEDO, Antônio Sérgio Torres ${ }^{2}$

\begin{abstract}
RESUMO: O presente trabalho visa a mostrar que o CCQ (Circulo de Controle de Qualidade) é conhecido como meio de diminuir os custos e aumentar a produtividade das empresas, que, no caso estudado a FIAÇÃO MAEDA, além de promover, paralelamente, incremento à satisfação no trabalho, promove também maior responsabilidade, integração e cooperação dos funcionários da empresa. Através deste artigo, queremos mostrar que o CCQ pode diminuir o custo de setores de uma determinada empresa e aumentar o controle e o processo de trabalho sobre o trabalhador.
\end{abstract}

Palavras-chave: Qualidade. Fiação de algodão. Controle de qualidade.

\section{CIRCLE OF QUALITY CONTROL AS TOOL FOR DECREASE OF COST IN AN INDUSTRY OF COTTON SPIN IN THE CITY OF ITUVERAVA}

\begin{abstract}
The present work aims to show that CCQ (I Circulate of Quality Control) is known as a way to reduce costs and to increase the productivity of the companies, that, in this studyd, the FIAÇÃO MAEDA, besides promoting, parallely, increment to the satisfaction in work, also promotes larger responsibility, integration and the employers' of the companies cooperation. Through this article, we want to show that CCQ can reduce cost of sections of a certain company and increase the control and the work process on the worker.
\end{abstract}

Keywords: Quality. Cotton Spin. Quality control.

\section{INTRODUÇÃO}

O estudo dos Círculos de Controle de Qualidade (CCQ) visa a conscientizar os operários e supervisores de quanto o círculo de controle de qualidade é importante dentro das organizações, na prática do trabalho em equipe, pois possibilita o crescimento humano através de uma constante troca de idéias e conhecimentos entre seus componentes. Para que tudo obtenha sucesso, é necessário que as soluções sejam conseqüências do esforço organizado de

Assim sendo, o presente estudo tem como objetivo analisar e compreender os processos de implantação do programa de círculo de controle de qualidade em uma indústria várias pessoas da mesma empresa; sendo assim, o CCQ também tem a função de ajudar as empresas a trazer benefícios para ela e para seus colaboradores.

que atua na área de fiação de algodão. Para tal será utilizado o estudo de caso referente

1 Bacharel em Administração Gestão de Negócios pela FFCL - Fundação educacional de Ituverava, com experiência profissional em empresas industriais, financeiras e prestadoras de serviços.

2 Doutorando em Engenharia de Produção. Prof. Fundação Educacional de Ituverava.e-mail: astpenedo@ yahoo com br

Nucleus, v. 5. n. 1 , abr. 2008 
à fiação de algodão da MAEDA AGROINDUSTRIAL S/A, que já utiliza, há quatro anos, o CCQ, como ferramenta para diminuição de custos indústrias, para realização de um estudo de caso com base em estudos bibliográficos a cerca do significado e da filosofia dos CCQ. Serão apresentadas, neste estudo, as ferramentas utilizadas para identificação de necessidade, analise do problema, definição do objetivo, seleção de possíveis soluções, execução da solução escolhida e apuração de resultados.

\section{CÍRCULO DE CONTROLE DE QUALIDADE - CCQ}

Segundo Chaves (2000), o Círculo de Controle de Qualidade - CCQ é um sistema para promover o trabalho em equipe, ajudar no crescimento humano por meio de idéias e conhecimentos entre seus componentes. As soluções são corretivas ou inovadoras, conseqüência do esforço organizado de várias pessoas. O CCQ é composto por pequenas equipes, formados por pessoas que exercem as mesmas atividades ou áreas parecidas que desenvolvem, voluntariamente atividades que proporcionam a melhoria dos resultados em qualidade, custos, atendimento, moral, meio ambiente e segurança. A equipe atua com participação total de cada pessoa, em reunião que ocupa, no máximo, quatro horas por mês, e que pode acontecer no horário de trabalho ou não.

De acordo com Chaves (2000), o fundamento do CCQ foi no Japão, depois da segunda guerra mundial. Em 1962, o japonês Prof. Kauru Ishikawa criou o CCQ, formado por colaboradores voluntários de empresas. Para que o trabalho seja mais alegre e mais comunicativo, tudo isso é liberado pelos supervisores, mas ainda não tinha sido posto em pratica.

Segundo Chaves (2000), o primeiro círculo foi posto em prática no Japão, em 1963, e uma estatística divulgada em 1964 mostrava que 95\% dos círculos eram em áreas de vendas e serviços e tinham uma medida de 4,2 idéias novas por ano. Já no Brasil, foi iniciado em 1971, em várias empresas brasileiras, sendo pioneiro na prática, depois do Japão, junto com a Coréia e a Tailândia.

Ao decidir fazer parte do CCQ, os colaboradores devem ter consciência de que o CCQ deve ser procedido através de conceitos, filosofia e objetivos. (CHAVES, 2000).

Ainda o mesmo autor salienta que os propósitos fundamentais do CCQ são:

- contribuir para a melhoria e desenvolvimento da empresa;

- respeitar a natureza humana, construindo um local de trabalho alegre e brilhante no qual valha a pena viver;

- desenvolver as possibilidades infinitas da capacidade mental humana e permitir a sua aplicação (CHAVES, 2000).

O ideal é que cada CCQ tenha, no mínimo, três e, no máximo, sete funcionários, e que cada empresa tenha, no máximo, oito grupos. Todas as decisões dos círculos são tomadas em conjunto, através de consenso. Esse projeto não é hierárquico, mas necessita de apoio do gestor da empresa: 
- é uma atividade voltada ao desenvolvimento das pessoas, principalmente, da capacidade de administrar a qualidade;

- os participantes são voluntários;

- o grupo tem total liberdade para a escolha dos lideres e secretários;

- o grupo escolhe o tema que quer discutir;

- o grupo analisa as idéias e as passa para os orientadores;

- os integrantes não têm compromisso com os resultados (NOGUEIRA; CHAVES; SANTOS, 2000).

As ferramentas adotadas para formação do CCQ são:

- brainstorming: tempestade de idéias - servem para estimular a criatividade das pessoas, gerando o maior número possível de idéias para solucionar os problemas das empresas. Essas ferramentas dão oportunidades iguais a todos os integrantes do grupo para darem opiniões sobre um determinado assunto (CHAVES, 2000);

- RAB: rapidez, autonomia e benefício - os problemas escolhidos no brainstorming são passados em três peneiras: Rapidez, Autonomia e Benefício. Por tanto, utiliza-se as perguntas para cada problema, atribuindo os pontos a cada peneira ou requisito. As perguntas são as seguintes (CHAVES, 2000): Em quanto tempo podemos solucionar este problema? Até onde podemos ir para resolver o problema? Que benefício a solução trará?

- diagrama de Causa e Efeito (espinha de peixe): são métodos particularmente efetivos de ajudar a pesquisar as raízes de problemas, através de questões como: o que, onde, como e por que estudar este problema (SLACK; CHAMBERS; JOHNSTON, 2002).

- 5 Porquês: É uma ferramenta que auxilia no aprofundamento da análise. Com essa ferramenta o grupo deve perguntar o porquê da ocorrência de um problema e, a cada causa encontrada, o porquê dos problemas. Para cada problema a ser estudado existe uma série de perguntas que determinam os 5 porquês (CHAVES, 2000).

\section{OBJETIVOS GERAIS DO CÍRCULO DE CONTROLE DE QUALIDADE - CCQ}

Segundo Facioli (1999), os objetivos gerais do CCQ são:

- ajudar os gerentes, supervisores e coordenadores a solucionar os problemas das empresas;

- sugerir métodos para melhoria da qualidade.

\section{CARACTERÍSTICAS DO CÍRCULO DE CONTROLE DE QUALIDADE - CCQ}

Segundo Chaves (2000), é necessário que cada grupo tenha suas características:

- voluntariedade; 
- continuidade;

- autonomia;

- objetivo;

- respeito à individualidade dos colegas;

- consenso e cooperação.

\section{METODOLOGIA}

Através do presente trabalho, discutir-se-á como o CCQ pode afetar na redução de custos dentro da fiação de algodão MAEDA AGROINDUSTRIAL S/A. Para realização da pesquisa de campo, foram realizadas visitas à empresa para o acompanhamento das reuniões de CCQ com os colaboradores, durante cinco meses. A implantação do CCQ foi dividida em 4 etapas.

Etapa 1: Escolha dos grupos, que são compostos por:

- coordenadores: pessoas que fazem parte da empresa, mas não têm vínculo com os grupos, e servem, apenas, de apoio;

- orientadores: elos entre funcionários e coordenadores;

- líderes: dirigem as reuniões e delegam as funções;

- secretário: cuida da parte de documentação;

- circulistas: pessoas que compõem o grupo.

Essa ordem de implantação deve ser seguida por todas as empresas que queiram implantar o CCQ.

Etapa 2: Escolha do problema

Depois do grupo formado, escolhe-se o problema, que, feito através do Brainstorming, (tempestade de idéias) todas as idéias são escritas em um papel e passadas para os coordenadores do CCQ.

Os coordenadores vão analisar e devolver as idéias, com, no máximo, quatro sugestões de problemas.

Para que sejam selecionados, todos os problemas passam por uma ferramenta que se chama RAB (rapidez, autonomia, benefício) que funciona como um filtro. O problema que for mais rápido para ser executado é o problema escolhido.

Etapa 3: Análise do problema

Depois do problema escolhido, ele tem que ser analisado.

Para essa análise, os colaboradores adotaram um outro sistema com o nome de diagrama de causa e efeito ou diagrama de Ishikawa, que também é chamado de espinha de peixe (nome mais popular).

\section{Etapa 4: Prática do CCQ}

Depois de analisado o problema, foram estudas as possibilidades de mudança, e é hora de colocar os trabalhos em prática. Esses trabalhos são mostrados aos coordenadores, e eles fazem algumas correções e depois aprovam. 
Com os trabalhos já aprovados, eles vão discutir as reduções de custos que vão beneficiar a empresa. A fiação Maeda tem trabalhos que já deram até $80 \%$ de redução de custo, o que é, para empresa, um benefício muito grande, pois, com essa redução, a empresa pode investir em treinamentos e palestras para seus colaboradores. Com esses resultados, os colaboradores ficam mais motivados a trabalhar na empresa.

Depois de tudo corrigido e aprovado, os colaboradores fazem uma apresentação para o presidente e diretores da empresa.

As autoridades presentes têm uma série de requisitos que as apresentações dos colaboradores têm que atingir. Os requisitos são:

- o tempo que eles determinam para apresentação;

- o modo de explicar o trabalho;

- a habilidade de lidar com o tema.

Depois que todos os trabalhos foram apresentados às autoridades, aplicam a nota e os ganhadores são presenteados, com viagens e brindes, mas nenhuma premiação é feita em dinheiro. Os trabalhos restantes também são aplicados dentro da empresa para melhoria da mesma, pois eles também vão fazer com que a empresa alcance a redução de custos.

\section{A EMPRESA EM ESTUDO}

O GRUPO MAEDA está no mercado há 77 anos, na região de Ituverava, a 410 km de São Paulo. É uma empresa familiar que já atravessa três gerações, sendo o fundador Tsunezaemon Maeda, que, em 1942, transferiu o comando da empresa para o primogênito Takayuki Maeda. O grupo começou a fazer seu próprio beneficiamento de algodão na cidade de Ituverava, em 1974. Com o passar dos anos, o grupo sempre inova os maquinários, e, desde então, o grupo Maeda não para de expandir, sempre se dedicando à agricultura, cultivando algodão, soja e milho, expandindo para Goiás, Mato Grosso e Bahia. O grupo Maeda tornou-se um dos maiores produtores de algodão do país, e está na liderança da agroindústria do algodão e, a cada dia, vem conquistando mais e mais mercados com beneficiamentos de algodão. Hoje, quem está na presidência da empresa é o filho mais velho de Takaiuki Maeda, Jorge Maeda.

O grupo, que é conhecido em outros estados e países como o "rei do algodão", não está expandindo somente na área de algodão, mas está crescendo em outros setores também. $\mathrm{O}$ grupo, em menos de 2 anos, já ocupa grandes lugares no mercado mundial, na área de gorduras vegetais e já tem idéia de entrar no ramo sucroalcooleiro pretendendo atingir o mesmo lugar do algodão.

A fiação Maeda trabalha, atualmente, com 120 funcionários diretos, sem contar com os funcionários contratados em alta temporada (época de safra). 


\section{ANÁLISE DOS RESULTADOS}

Para analisar os resultados (benefícios) que o CCQ trouxe para a empresa e colaboradores, foi feita uma pesquisa através de questionário com todos os colaboradores que participaram do CCQ, totalizando quarenta funcionários, o que comprova que o CCQ, realmente, reduz o custo da fiação de algodão e faz com que os colaboradores se integrem um com o outro, o que pode ser observado nos gráficos abaixo. Os colaboradores comentam que, após implantação do CCQ, mudaram o jeito de agir e pensar e, que não imaginavam que o CCQ fosse trazer tantos benefícios para suas vidas e garantem que, após a implantação, ficaram mais motivados ao trabalho.

Nesta figura, podemos observar que dos quarenta funcionários $60 \%$ são homens e $40 \%$ são mulheres, podendo notar que o CCQ é um método adotado nas empresas sem distinção de sexo. Falando em números absolutos são 24 homens e 16 mulheres.

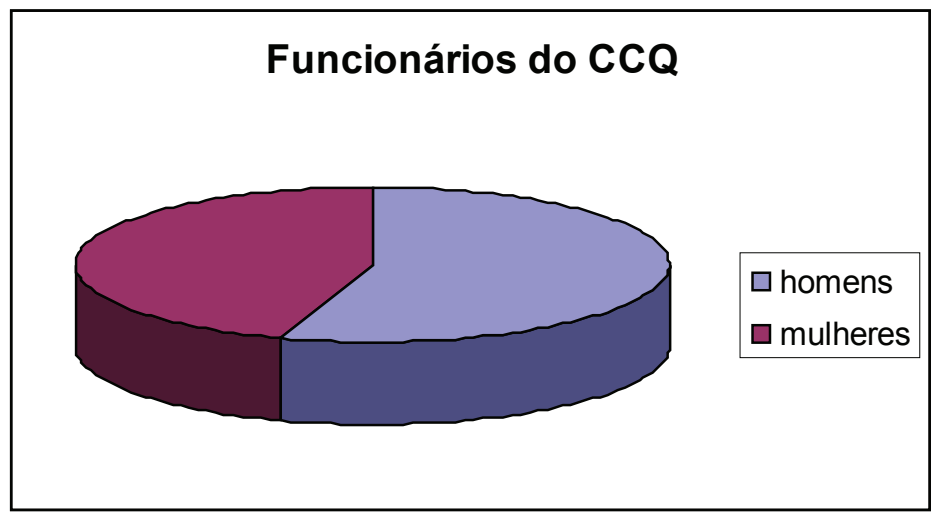

Figura 1: Quantidades de colaboradores que participam do CCQ.

Podemos notar que, na figura abaixo, 95\% dos funcionários participantes do CCQ se envolvem e participam espontaneamente e se de dedicam, enquanto apenas $5 \%$ dos funcionários entrevistados não são participantes dedicados ao CCQ. Isso, em números absolutos, mostra que 38 funcionários participam constantemente do CCQ, e 2 funcionários participam por influência de outros funcionários. 


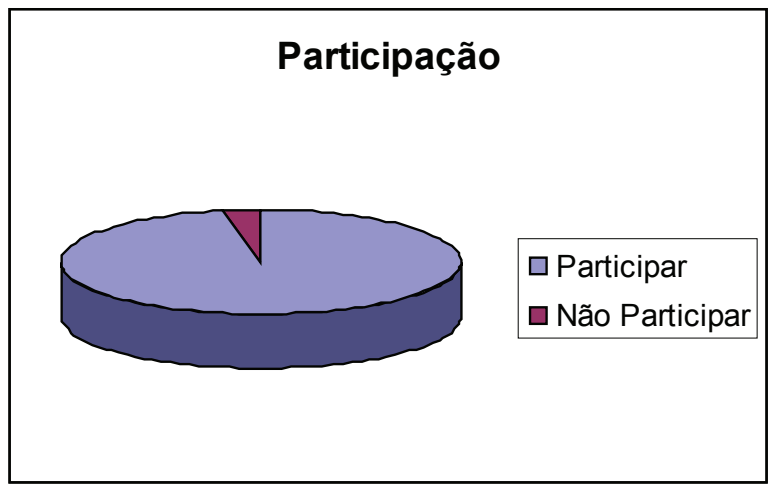

Figura 2: Medir o grau de envolvimento e participação dos colaboradores.

Na figura abaixo, nota - se que 55\% dos funcionários afirmam que o CCQ traz benefícios para empresa e $45 \%$ dos funcionários admitem que o CCQ traz benefícios para a vida pessoal e profissional.

Sendo assim, transferindo os valores de porcentagens para valores absolutos, nota-se que 22 funcionários admitem que o CCQ traz benefícios para empresa, e os 18 funcionários restantes notam que o CCQ trouxe benefícios tanto pra a sua vida pessoal quanto profissional.

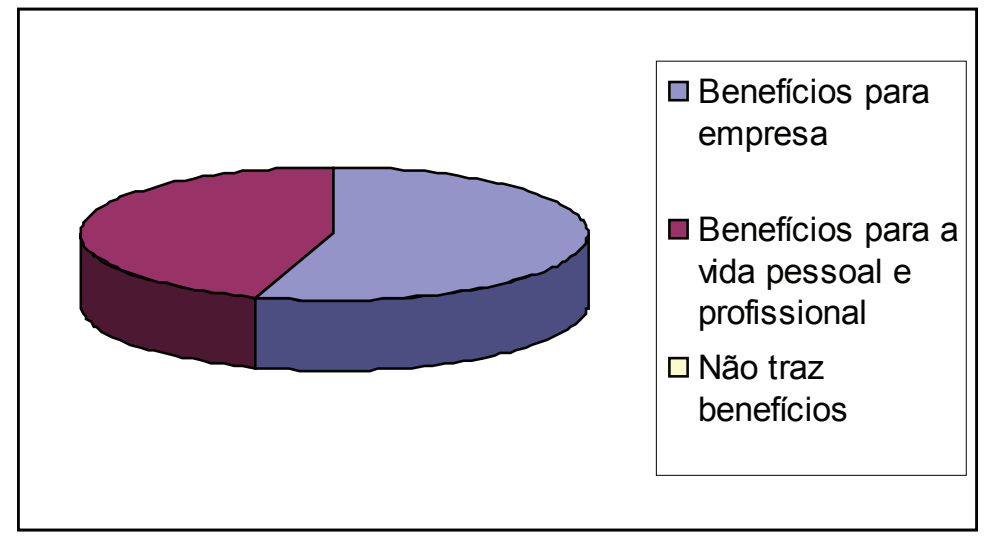

Figura 3: Medir grau de benefícios para empresa e para a vida pessoal dos funcionários.

Na figura abaixo, observa-se que 95\% dos funcionários notam que há redução de custos na indústria de fiação, enquanto apenas 5\% acham que o CCQ não é capaz de reduzir custos de uma empresa. Transformando esses valores em números absolutos, 38 funcionários já comprovaram que o CCQ traz ótimas reduções de custos para a empresa, e os outros 2 funcionários são novatos no CCQ e ainda não viu redução de custos para a empresa. 


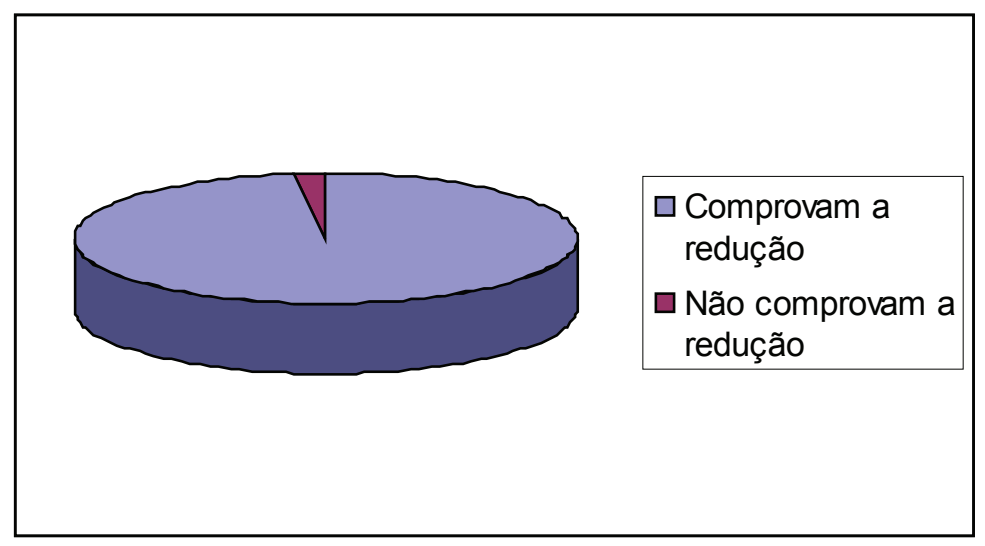

Figura 4: Colaboradores já comprovaram que o CCQ traz redução de custo para empresa.

Essa figura abaixo é para medir o grau de comprometimento dos funcionários com o CCQ e, nota-se que $90 \%$ dos funcionários são totalmente comprometidos com o CCQ e se empenham com o CCQ, dedicando o tempo que for necessário, enquanto apenas 10\% deixam se levar por influência dos colegas que não participam do CCQ. Transformando esses valores em números absolutos, notamos que 36 funcionários são comprometidos, enquanto 4 não são comprometidos.

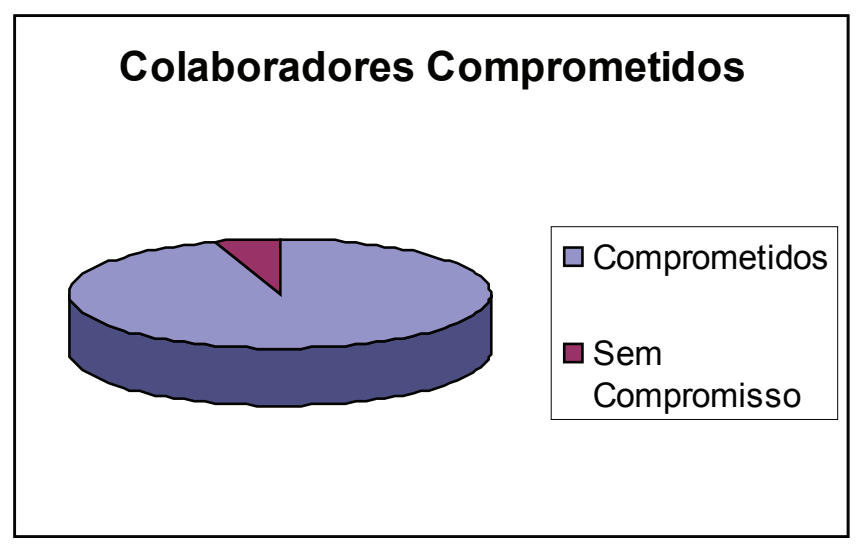

Figura 5: Colaboradores comprometidos com objetivos e resultados do CCQ.

\section{CONSIDERAÇÕES FINAIS}

Através do presente trabalho, pode-se concluir que o CCQ é uma forma de envolver os colaboradores dentro dos problemas da empresa e facilitar o entrosamento deles com seus colegas. Podemos notar que o CCQ também é uma forma de reduzir custos e trazer benefícios para a empresa com poucos e pequenos detalhes. Os colaboradores ficam mais motivados a trabalhar, pois notam que suas opiniões são postas em prática e, geralmente, ficam contentes 
com o resultado. Aprendem, também, com os resultados e melhoram a vida profissional e a vida pessoal, alem de ajudarem a empresa que trabalha. Ficam motivados, a diretoria da empresa conversa com os funcionários e mostra a importância do CCQ dentro da empresa sem obrigálos a nada. O CCQ não tem hierarquia, todos conversam de igual para igual sem distinção e preconceito o que é muito importante para a empresa.

A empresa estudada utiliza este método de qualidade há quatro anos e, neste tempo, geralmente, os problemas apresentados foram solucionados com grande sucesso.

\section{REFERÊNCIAS}

CARDOSO, F.F.; MARTINELLI. F.A. CCQ: círculo de controle de qualidade. 2000. Disponível em: http://tgp-mba.pcc.usp.br/TG-005/tg-005-aula2-g5.doc. Acesso em: 10 jul. 2007.

CHAVES, N.M.D. Solução em equipe. 4.ed. Belo Horizonte: Desenvolvimento Gerencial, 2000.

FASCIONI.L. Círculo de controle de qualidade. Disponível em: $<$ http://www.ligiafascioni. com.br/aulas/CCQ_design.pdf>. Acesso em: 10 jul. 2007.

NOGUEIRA. J.C.; CHAVES. N.M.D.; SANTOS R.F. Gerenciamento do CCQ. Belo Horizonte: Desenvolvimento Gerencial, 2000.

SLACH, N.; CHAMBERS, S.; JOHNSTON. R. Administração da produção. 2.ed. São Paulo: Atlas, 2000. 